\title{
Ensinar a ler: finalidades docentes no contexto da alfabetização
}

\author{
Alexsandra Felix de Lima Sousa \\ Débora Amorim Gomes Costa-Maciel \\ Universidade de Pernambuco (Brasil)
}

\section{Resumo}

Este artigo objetiva refletir a respeito das finalidades docentes para o ensino da leitura no primeiro ano do ciclo de alfabetização. A relevância de tal discussão está amparada no fato de que, mesmo em uma sociedade essencialmente grafocêntrica, a alfabetização - ensino da leitura e escrita - ainda representa um desafio para as redes de ensino do Brasil. Como opção metodológica, foi adotada uma abordagem qualitativa em que os dados foram coletados a partir de entrevista semiestruturada com quatro professoras alfabetizadoras atuantes em escolas da rede municipal do Recife. O aporte teórico está pautado nos estudos de Soares (1998, 2015, $2016)$; Lerner (2002); Cafiero (2005, 2010); Leal e Melo (2006), entre outros. A partir da imersão nos dados, foi observado que as docentes desenvolvem estratégias para o ensino da leitura em que as intenções primordiais consistem em favorecer aos (às) estudantes o estabelecimento de relações com os textos para aquisição de saberes escolares e extraescolares, além de proporcionarem uma formação leitora que contemple a dimensão do prazer no ato de ler.

Palavras-chave: Alfabetização. Ensino de leitura. Finalidades para ensino da leitura. Professoras alfabetizadoras.

\section{Teaching to read: teachers' purposes in the context of literacy}

\section{Abstract}

This article aims to reflect on the teachers' purposes for the teaching of reading. The relevance of such a discussion is supported by the fact that, even in an essentially graphocentric society, literacy - the teaching of reading and writing - still represents a challenge for Brazilian education networks. As a methodological option, a qualitative approach was adopted, in which data were collected from semi-structured interviews with four literacy teachers working in schools in the municipal network of Recife. The theoretical framework is based in Soares (1998, 2015, 2016); Lerner (2002); Cafiero (2005, 2010); Leal and Melo (2006), among others. From the immersion in the data, it was observed that the teachers develop reading teaching strategies in which the main intentions consist in to favor students the establishment of relations with the texts, for the acquisition of school and out-of-school knowledge, in addition to provide a reading formation that contemplates the dimension of pleasure in the act of reading.

Keywords: Literacy. Reading teaching. Purposes for teaching reading. Literacy teachers. 


\section{Enseñar a leer: propósitos de los profesores en el contexto de la alfabetización}

\section{Resumen}

Este artículo pretende reflexionar sobre los propósitos docentes para la enseñanza de la lectura en el primer año del ciclo de alfabetización. La relevancia de esta discusión se sustenta en el hecho de que, incluso en una sociedad esencialmente grafocéntrica, la alfabetización - la enseñanza de la lectura y la escritura - todavía representa un desafío para las redes educativas brasileñas. Como opción metodológica, se adoptó un enfoque cualitativo, en el cual se recogieron datos a partir de entrevistas semiestructuradas a cuatro alfabetizadoras que trabajan en escuelas de la red municipal de Recife. El aporte teórico se basa en los estudios de Soares (1998, 201 5, 2016); Lerner (2002); Cafiero (2005, 2010); Leal y Melo (2006), entre otros. A partir de la inmersión en los datos, se observó que las profesoras desarrollan estrategias para la enseñanza de la lectura en las que las intenciones primordiales consisten en favorecer a los estudiantes el establecimiento de relaciones con los textos para la adquisición de conocimientos escolares y extraescolares, además de proporcionar una formación lectora que contemple la dimensión del placer en el acto de leer.

Palabras clave: Alfabetización. Enseñanza de la lectura. Finalidades de la enseñanza de la lectura. Profesoras alfabetizadoras.

\section{Introdução}

O desenvolvimento de práticas efetivas de ensino da leitura que garantam a alfabetização das crianças configura-se como um desafio para as redes de ensino no Brasil (SOUSA, 2019). Dados do Núcleo de Avaliação de Rede do Recife (NARE) evidenciam que a média de acertos de estudantes do $3^{\circ}$ ano no eixo de leitura da avaliação diagnóstica de Língua Portuguesa, realizada em 2017, foi de 65,4\%. Já o resultado da Avaliação Nacional da Alfabetização (ANA) realizada em 2016, aponta que somente 1 1\% dos estudantes avaliados estavam no nível 4, ou seja, apresentaram domínio das habilidades de leitura. Vemos, desse modo, a urgente necessidade de investir em práticas efetivas de ensino da leitura, uma vez que cerca de um terço dos(das) estudantes da rede de ensino do Recife concluem o ciclo de alfabetização sem consolidar os objetivos de aprendizagem de leitura, aferidos na avaliação de rede. Nesse mesmo panorama, também foi constatado que o exame nacional da alfabetização apresenta indicadores que revelam um número considerável de estudantes que concluem o ciclo de alfabetização sem fazer uso competente da linguagem escrita. 
caráter relevante que descrevemos aqui ancora-se, por um lado, nesse cenário revelado por avaliações em larga escala que demonstra a condição da alfabetização de estudantes do ciclo alfabetizador da rede de Recife. Por outro lado, na perspectiva de aquisição da linguagem escrita enquanto direito, presente em documentos oficiais e defendida pela academia, Soares (2015, p. 2), por exemplo, afirma que se deve garantir a todas as crianças a efetivação do direito da aprendizagem da leitura e da escrita, oferecendo-thes "[...] as condições não só de prosseguirem com sucesso sua escolarização, mas, sobretudo, de se apropriarem de competências indispensáveis para a plena inserção na vida social e profissional [...]"com o domínio da leitura e da escrita.

Diante da prerrogativa de aquisição da leitura, enquanto direito a ser garantido, e ao aferir que as crianças da rede do Recife, nosso espaço de atuação profissional há 15 anos, concluem o período escolar próprio para a alfabetização sem a garantia de tal direito, nos inquietamos frente ao que se delineia como uma negação de diretos e uma dívida social a ser quitada. $\bigcirc$ que nos leva a algumas questões de partida: para que ensinar a ler na alfabetização? Quais objetivos norteiam as práticas de ensino inicial da leitura? $\bigcirc$ que docentes aspiram para seus(suas) estudantes ao tratar desse eixo didático?

Nesse sentido, o foco do nosso objeto de discussão consiste em refletir a respeito das finalidades docentes para o ensino inicial da leitura. Tal discussão, pautada numa reflexão sobre as práticas de ensino para a formação leitora, pode viabilizar caminhos para o desenvolvimento de estratégias didáticas que favoreçam a alfabetização.

Este artigo está estruturado de modo que inicialmente fazemos algumas considerações teóricas acerca da problemática envolvendo o trato com a leitura e os objetivos de ensino docente e, na sequência, apresentamos a base teórico-metodológica que sinaliza as nossas escolhas para a investigação da temática. Em seguida, abordamos os dados tratados à luz da teoria que envolve a discussão sobre o tema. Por fim, faremos algumas considerações finais que buscam destacar os achados de nossa reflexão. Contudo, o artigo não busca encerrar o tema em si, mas visa a promover aberturas para que o diálogo continue. 


\section{Perspectivas sobre o ensino inicial da leitura: aporte teórico}

ato de ler é complexo e envolve inúmeros sentidos, conforme a ação e o contexto em que se emprega a leitura. Diante disso, diferentes campos do conhecimento humano buscam definições e empregos para o termo. Neste artigo, iremos discutir as perspectivas que se voltam à leitura de textos escritos em ambiente escolar, sobretudo no primeiro ano do ensino fundamental.

Ressaltamos, que, mesmo no que se refere à leitura de textos, o termo leitura assume uma característica de heterogeneidade, não só em relação ao objeto da leitura, mas aos modos e atitudes requeridas de quem lê. Dessa forma, no que diz respeito à leitura de textos escritos, não é possível encontrar apenas uma designação, uma vez que o conceito de leitura está diretamente relacionado à concepção de linguagem que o orienta.

Numa concepção de linguagem enquanto representação do pensamento, temos: "A expressão se constrói no interior da mente, sendo sua exteriorização apenas uma tradução" (TRAVAGLIA, 1996, p. 21). Nessa concepção, ler é uma atitude individual e estável que apenas traduz o pensamento do autor, sem interferência do leitor. Existe também o enfoque em que a linguagem é vista sob uma ótica de instrumento de comunicação. Nela, a leitura assume o status de domínio de código em que o leitor é aquele capaz de receber a mensagem de um emissor e transformar os sinais em informação (TRAVAGLIA, 1996). Nas duas acepções, o ensino da leitura está voltado para a garantia de habilidades que favoreçam ao estudante a extração de informações presentes no texto, seja para compreender o pensamento do autor, seja para captar uma mensagem.

Há ainda uma terceira concepção de linguagem que norteia o conceito de leitura, a linguagem como interação. A esse respeito, Koch (2002, p. 17) afirma que "[...] o texto passa a ser considerado o próprio lugar da interação e os interlocutores, como sujeitos ativos que - dialogicamente - nele se constroem e são construídos [...]". Vemos, nessa concepção, a leitura como um processo dinâmico em que interlocutores - autor/leitor - dialogam, constroem e reconstroem experiências e conhecimentos em que o ensino da leitura precisa se envolver, desenvolvendo uma multiplicidade de estratégias para a formação de leitores com ampla capacidade de interagir com o escrito. Assumimos, nesta discussão, a vertente de leitura enquanto atividade social de interação. 
Após discorrermos sobre os conceitos de leitura, conforme as concepções de linguagem, pensemos a leitura enquanto objeto do conhecimento. Uma vez que a leitura é parte dos currículos da educação básica e atribui-se à escola o papel de desenvolver práticas para o ensino da leitura. Leal e Melo (2006), ao tratarem da leitura enquanto objeto do conhecimento na escola, destacam:

[...] podemos afirmar que a leitura é um dos eixos principais a ser priorizado no Ensino Fundamental. Ensinar a ler é uma ação inclusiva, pois possibilita ao indivíduo ter acesso a diferentes informações e participar de eventos de letramento que ampliam sua participação na sociedade, ou seja, saber ler possibilita ao indivíduo inserir-se em situações diversas próprias da nossa sociedade letrada em que o texto escrito é usado para mediar as interações. Colabora, portanto, para a construção da identidade cidadã dos alunos (LEAL; MELO, 2006, p. 42).

Embora a leitura seja objeto de conhecimento no âmbito escolar, não é só na escola que se ensina e se aprende a ler. Uma vez que a leitura é um ato de natureza sociocultural - ainda que envolva aspectos cognitivos -, seu ensino e aprendizagem requerem ações específicas que não se restringem ao espaço escolar, pois as crianças convivem desde muito cedo com situações de leitura e assim iniciam sua formação leitora.

Ninguém nasce sabendo ler: aprende-se a ler à medida que se vive. Se ler livros geralmente se aprende nos bancos da escola, outras leituras se aprendem por aí, na chamada escola da vida: a leitura independe da aprendizagem formal e se perfaz na interação cotidiana com o mundo das coisas e dos outros (LAJOLO, 2004, p. 7).

Como vemos na declaração de Lajolo, geralmente se aprende leitura dos livros na escola, mas o sentido do que se lê também precisa ser aprendido. Tal fenômeno pode ocorrer por meio de ações docentes que propiciem mais do que um contato com o escrito, é necessário serem oportunizadas a construção de significados sobre o que se lê. $\bigcirc$ desenvolvimento de atividades voltadas para o ensino da leitura, representa um desafio, pois entendemos o ato de ler como algo complexo, que vai além da conversão de grafemas em fonemas, é necessário abranger as multifacetas de seu ensino. 
Haja vista os desafios que circundam o ensino da leitura, é de suma importância delimitar qual o objeto de ensino da leitura. Temos na declaração "[...] ler é um processo de interação entre leitor e texto [...]" (SOLÉ, 1998, p. 22) uma abordagem sociointeracionista da leitura em que o texto é o objeto de ensino da leitura. Se é objeto de ensino, deve ser também objeto de aprendizagem. Para tanto, faz-se necessário desenvolver estratégias de leitura que oportunizem o diálogo com os textos.

Sobre as estratégias de leitura, Solé (1998) e Cafiero (2005) nos apresentam procedimentos que podem configurar-se como importantes aliadas do fazer pedagógico nas salas de aula de alfabetização. Em seus estudos, as autoras descrevem estratégias que devem acontecer antes, durante e depois da leitura. Também chamam a atenção para a importância da mediação docente em cada uma das etapas que devem ser desenvolvidas a partir de atividades individuais e/ou coletivas com diferentes modalidades dando diferentes oportunidades de atuação aos sujeitos em processo de formação leitora.

Nesse processo de formação de leitura, existem comportamentos que também precisam ser ensinados/aprendidos antes mesmo da aprendizagem convencional da leitura. Não se tratam de atividades, mas de conteúdos que precisam ser trabalhados desde os primeiros anos de escolarização.

Entre os comportamentos do leitor que implicam interações com outras pessoas acerca dos textos, encontram-se, por exemplo, as seguintes: comentar ou recomendar o que se leu, compartilhar a leitura, confrontar com outros leitores as interpretações geradas por um livro ou uma notícia, discutir sobre as intenções implícitas nas manchetes de certo jornal [...] Entre os mais privados, por outro lado, encontram-se comportamentos como: antecipar o que segue no texto, reler um fragmento anterior para verificar o que se compreendeu, quando se detecta uma incongruência, saltar o que não se entende ou não interessa e avançar para compreender melhor, identificar-se com o autor ou distanciar-se dele assumindo uma posição crítica, adequar a modalidade de leitura - exploratória ou exaustiva, pausada ou rápida, cuidadosa ou descompromissada... aos propósitos que se perseguem e ao texto que se está lendo [...] (LERNER, 2002, p. 62).).

A partir da descrição de Lerner, percebemos os comportamentos do leitor, orientados a partir das finalidades que motivam as leituras. $\bigcirc$ que fará da leitura de textos um objeto de aprendizagem será o que instiga a busca 
pelas interações com o texto, daí a importância de atribuir sentido ao que se lê na escola. Não se admite mais um ensino da leitura voltado para atender às expectativas que se circunscrevam ao âmbito da sala de aula, mas para uma formação leitora que atenda às perspectivas de participação social. A esse respeito Cafiero afirma:

As exigências da sociedade moderna têm apresentado para a escola o desafio de formar cada vez melhor seus alunos, têm exigido que a escola contribua efetivamente para aumentar o grau de letramento de seus alunos. Isto é, para torná-los cada vez mais capazes de usar a leitura e a escrita em suas práticas sociais e não somente em tarefas escolares. Não basta apenas se apropriar da tecnologia da escrita, ou estar alfabetizado. É preciso possuir, entre outras, habilidades de ler, compreender e usar textos presentes no nosso dia-a-dia [...]. Possuem também um grau elevado de letramento aqueles que tomam a leitura/escrita para passar o tempo, para descansar e relaxar, que fazem uso dela em seus momentos de lazer (CAFIERO, 2005, p. 9-10).

Ao afirmar: "Não basta apenas se apropriar da tecnologia da escrita, ou estar alfabetizado" a autora chama a atenção para o fato de que ensinar a ler não se restringe ao ensino dos princípios do sistema de escrita alfabético, mas que há muitas outras habilidades que precisam ser ensinadas e aprendidas. Quando se aprende a ler, a capacidade de compreender textos não é incluída, isso faz parte de um processo que envolve práticas docentes intencionais que devem ser cuidadosamente planejadas. Para tanto, faz-se necessário que desde os primeiros anos de escolarização sejam desenvolvidas práticas de ensino da leitura voltadas para a dimensão dos usos sociais dos textos que circulam e são lidos no cotidiano, mas sem olvidar a dimensão estética da leitura. A esse respeito, Kramer (2001, p. 64), defende que "[...] no tocante ao ensino da língua escrita, não se pode prescindir da literatura, pois é ela que favorece a prática de ler, a interação com os livros, a atribuição de significados ao texto, além de evidentemente propiciar o prazer de ler".

ensino da leitura, portanto, deve estar comprometido com a formação de leitores(as) para os diversos fins sociais e culturais que os textos assumem no cotidiano das crianças em processo de alfabetização, a partir do uso de estratégias variadas e diferentes modos de organização textual, adequados aos diversos propósitos comunicativos. 
Desse modo, é preciso ajudar os alunos a desenvolver capacidades que possibilitem atender a diferentes finalidades de leitura, presentes na escola e fora dela. Um primeiro passo para isso é fazer com que os alunos tomem consciência sobre os diferentes modos de ler, relacionados aos diferentes propósitos de leitura na sociedade (LEAL; MELO, 2006, p. 42).

Frente a tantas demandas relacionadas ao ensino da leitura, o(a) professor(a) alfabetizador(a) precisa atuar de modo a favorecer a aquisição da leitura na escola, sem que sua função sociocultural seja descaracterizada. Para tanto, é indispensável o desenvolvimento de ações formativas específicas e contínuas que habilitem os (as) docentes para o trato com os aspectos cognitivos, culturais e sociais, que envolvem o ensino da língua escrita.

\section{Procedimentos metodológicos}

Este artigo resulta da coleta e análise de dados, vamos descrever os percursos trilhados para mais ampla compreensão de como foram obtidos.

Inicialmente, optamos por uma trajetória metodológica com uma abordagem qualitativa, numa perspectiva interpretativo-interacionista, com subsídios da metodologia interativa, desenvolvida a partir dos estudos de Oliveira (2001), a partir dos quais desenvolvemos entrevistas semiestruturadas com 4 (quatro) docentes atuantes no $1^{\circ}$ ano do ciclo alfabetizador da rede municipal de ensino do Recife, doravante identificadas com os seguintes nomes fictícios: Adhara, El-1 (ensino fundamental, $1^{\circ}$ ano); Altair, El-2 (ensino fundamental, $2^{\circ}$ ano); Nashira, El-3 (ensino fundamental, $3^{\circ}$ ano) e Zaniah, El-4 (ensino fundamental, $4^{\circ}$ ano).

A seleção dos sujeitos pautou-se em alguns critérios, entre os quais: a) ser docente de cada uma das quatro Regionais - 01 (Centro-Norte); 02 (Nordeste); 03 (Oeste-Sudoeste) e 04 (Sul) - em que se divide a Secretaria de Educação do Recife, nas quais estão organizadas as 310 unidades de ensino da rede municipal; b) atuar na regência de turma do primeiro ano do ciclo de alfabetização; c) possuir graduação com habilitação em licenciatura; d) não possuir experiência com formação de professores, a fim de evitar que o sujeito apresentasse justificativas sobre suas práticas enquanto formador de professores em detrimento de suas demandas para o ensino inicial da leitura; e) aceitar participar das etapas de coleta dos dados; f) assinar o termo de 
consentimento livre e esclarecido (TCLE), com vistas a cumprir as dimensões éticas da pesquisa.

Frente à seleção dos sujeitos, realizamos as entrevistas que forneceram dados a partir de duas etapas. Primeiro, a captação de respostas de cada professora e, em seguida, os comentários realizados por cada docente às respostas dos pares em relação aos mesmos questionamentos. Para o acesso à leitura das respostas dos pares, após a finalização da entrevista individual, disponibilizamos o registro escrito com a resposta das entrevistadas anteriores, que tiveram suas falas gravadas em áudio e transcritas. Apenas a primeira docente entrevistada teve acesso às respostas dos pares meses após a primeira abordagem, haja vista o caráter cumulativo do percurso metodológico.

Os dados obtidos tanto nas entrevistas individuais (EI) quanto nas entrevistas com acesso às respostas dos pares (EARP) foram submetidos à análise de conteúdo categorial de Bardin (1977). Para a discussão dos dados obtidos, buscamos aporte em pesquisadores(as) diversos(as), entre os quais: Solé (1998); Kramer (200 1); Lerner (2002); Leal e Melo (2006); Cafiero (2005, 2010); Soares (2015), entre outros (as).

\section{Finalidades do ensino da leitura: resultados e discussão}

As ações docentes, assim como as estratégias didáticas mobilizadas são desenhadas a partir de objetivos, estejam estes implícitos ou explícitos. Outrossim, é possível afirmar que o estabelecimento das finalidades do ensino da leitura relaciona-se intrinsecamente à nossa concepção de leitura Embasadas por esse olhar, nos debruçamos a refletir a respeito das finalidades das docentes, sujeitos de nossa pesquisa, para o ensino da leitura aos seus(suas) estudantes do primeiro ano do ciclo de alfabetização. Acreditamos que, a partir do delineamento de tais intenções pedagógicas, é possível compreender não somente o que as mobiliza, mas também como veem seu papel na formação leitora dos(as) estudantes e como desenvolvem suas ações de ensino, com vistas a alcançar as referidas finalidades. 


\section{Entrevista individual (El)}

Vejamos como as professoras entrevistadas se colocaram ao serem questionadas sobre as finalidades do ensino da leitura no ano escolar em que elas atuam, $1^{\circ}$ ano do ensino fundamental:

Ensino a ler para que, a partir da leitura, a criança possa entender todos os outros assuntos, todas as outras disciplinas. Enquanto o aluno não lê, ele apresenta uma maior dificuldade com as outras matérias e com outros conteúdos, seja ele qual for. [...] Considerando que a criança já tem uma leitura de mundo, que chamamos de conhecimento prévio [...] (ADHARA, 2018).

$[\ldots]$

É que eles sintam prazer em ler. Antes de tudo, ele tem que ver um livro e saber que ali ele vai sentir prazer (ALTAIR, 2018).

$[\ldots]$

É que os alunos aprendam de fato, reconheçam tudo à sua volta (NASHIRA, 2018).

$[\ldots]$

Que eles compreendam o que leem, inicialmente, pelas leituras de imagem e, depois, compreendam todas as leituras à sua volta (ZANIAH, 2018).

Adhara (2018) partilha que, no eixo do ensino de leitura, a sua prática é norteada pela intenção pedagógica de desenvolver habilidades leitoras. A docente parece nos indicar, inicialmente, que a sua preocupação está orientada para a aquisição pelos(as) estudantes de saberes escolares. Vemos essa dimensão quando ela afirma: "Ensino a ler para que, a partir da leitura, a criança possa entender todos os outros assuntos, todas as outras disciplinas" (Adhara, 2018). Além da relevância pedagógica, a finalidade referida pela professora encontra paralelo com os objetivos de leitura elencados por Solé (1998) que, entre outros, define: "[...] ler para procurar uma informação concreta [...] para realizar uma determinada atividade" (SOLÉ, 1998, p. 22).

Embora seja evidente a finalidade de ensino voltada para saberes escolares, presentes nos termos de sua fala - "conteúdos" "matérias" "disciplinas" - questionamo-nos, quando se refere a "outros assuntos", a professora considere também, diferentes práticas sociais que envolvem a leitura, uma vez que, mais adiante em sua fala, há um destaque para os conhecimentos prévios dos(as) estudantes a partir da leitura de mundo. 
Para Adhara (2018) "[...] enquanto o aluno não lê, ele apresenta uma maior dificuldade com as outras matérias e com outros conteúdos, seja ele qual for $[\ldots]^{\prime \prime}$. Inferimos a partir dessa fala que a professora considera a leitura convencional como requisito para a habilidade de interpretar textos. A esse respeito, precisamos considerar que, de fato, quando o(a) estudante consegue ler bem e com autonomia, é capaz de retornar a trechos lidos para verificar as informações, avançar na leitura para encontrar elementos que o(a) ajudem na compreensão, conforme descrito por Lerner (2002), o que favorece as práticas de leitura. Entretanto, tal ação não se origina do fato de conseguir decifrar os signos linguísticos e nem se estabelece de forma espontânea. Assim, para que haja tal desenvolvimento no ato de interagir com os textos escritos, o papel do(da) docente é primordial. A esse respeito, Cafiero afirma:

Então, quando um aluno lê e afirma: não entendi nada, não adianta o professor dizer: leia de novo que as informações estão aí. $\bigcirc$ aluno pode ter decodificado e saber exatamente que palavras e frases estão lá, mas, se não conseguir estabelecer relações entre o que decodificou e seus conhecimentos anteriores, ele não compreenderá. É preciso, então, que o professor forneça a ele uma base de conhecimentos para que ele processe o texto coerentemente (CAFIERO, 2005, p. 17).

Nesse fragmento, a autora defende que é preciso articular as informações presentes no texto com seus conhecimentos anteriores para o(a) estudante compreender o que leu. Reconhece, assim, a importância da valorização por parte da escola dos conhecimentos prévios dos(as) aprendizes. Tal valorização está presente no trecho de fala da docente: "[...] considerando que a criança já tem uma leitura de mundo, que chamamos de conhecimento prévio[...]" (ADHARA, 2018).

No que diz respeito ao questionamento sobre as finalidades do ensino da leitura no ano escolar em que atua, a professora Altair (2018) direciona sua resposta para um dos elementos relativos aos objetivos para a leitura, o prazer. Para ela, o importante "é que eles sintam prazer em ler. Antes de tudo, ele tem que ver um livro e saber que ali ele vai sentir prazer". A referência ao prazer enquanto elemento mobilizador da intenção pedagógica consiste numa prática que Geraldi (1984, p. 86) apresenta como requisito para o sucesso no ensino e na aprendizagem da leitura: "Recuperar na escola e trazer para dentro dela 
o que dela se exclui por princípio - o prazer - me parece o ponto básico para o sucesso de qualquer esforço honesto de incentivo à leitura."

A esse contexto de fala em que o ensino da leitura esteja relacionado ao prazer acrescentamos a afirmação de Cafiero (2005, p. 42): "A escola é o lugar de ensinar a ler. Mas é possível criar condições para que essa aprendizagem seja, o mais possível, próxima de uma situação real de leitura". Temos assim a defesa de que a didatização da leitura não esteja condicionada a ocorrer de modo distanciado da realidade e destituída de sentidos, e acreditamos que o ensino da leitura a partir de situações reais consiste em importante elemento que pode favorecer o desenvolvimento de aprendizagens significativas e prazerosas. Criadas as condições necessárias, os(as) estudantes podem estabelecer conexões efetivas entre o que constroem e ressignificam na escola em relação às práticas de leitura, e o que vivenciam em diferentes esferas do convívio social.

A professora Nashira (2018), por sua vez, explicita que a sua prática é norteada pelo desejo de que os(as) alunos(as) "[...] aprendam de fato, reconheçam tudo à sua volta". Ao dizer "aprendam de fato", é provável que a professora se refira ao domínio das capacidades requeridas ao leitor. Sobre as

12 capacidades de leitura, Cafiero argumenta:

Quanto à natureza das capacidades de leitura, as mais simples, como as de localizar, identificar, apontar tendem a ser desenvolvidas no início do processo. O leitor pode conseguir mais facilmente resolver questões em que basicamente volta ao texto para localizar [...]. O desenvolvimento de outras capacidades como as de inferir, estabelecer relações de causa, consequência, finalidade, compreender globalmente, perceber uma crítica expressa, perceber a força argumentativa do uso de determinados recursos linguísticos, perceber ironia ou humor, por exemplo, tende a ser mais complexo e demorado. No entanto, o grau de facilidade ou dificuldade de uma tarefa vai depender do texto que está sendo lido (CAFIERO, 2010, p. 93).

Na lista de capacidades leitoras elencadas pela autora, encontramos não apenas a sua descrição, mas o seu grau de complexidade. Portanto, as capacidades ou habilidades de leitura, ou ainda, os objetivos de aprendizagem demandam estratégias específicas para o ensino como designadas na proposta curricular do Recife. 
Já no trecho "reconheçam tudo à sua volta", temos uma afirmação que nos leva a ponderar que a professora Nashira (2018) considera a leitura como fator que oportuniza ao(à) estudante uma compreensão que vai além do espaço escolar, que o(a) favorece a operar os usos sociais da leitura. Tal pensamento coaduna com o que Lerner aponta como um dos desafios da escola ao ensinar a cultura escrita aos(às) estudantes:

[...] incorporar todos os alunos à cultura do escrito é o de conseguir que todos seus ex-alunos cheguem a ser membros plenos da comunidade de leitores e escritores. Participar na cultura escrita supõe apropriar-se de uma tradição de leitura e escrita, supõe assumir uma herança cultural que envolve o exercício de diversas operações com os textos e a colocação em ação de conhecimentos sobre as relações entre os textos; entre eles e seus autores; entre os próprios autores; entre os autores, os textos e seu contexto [...] (LERNER, 2002, p. 17).

Seguimos com a fala da professora Zaniah (2018) sobre a finalidade do ensino de leitura: "Que eles compreendam o que leem [...]". Encontramos aqui o que podemos atribuir a um ensino voltado para a construção da compreensão leitora, ao que Brandão (2006, p. 61) define como "[...] resultado da busca de sentido empreendida pelo leitor diante dos textos com os quais se depara". Tal busca de sentidos não se estabelece de maneira solitária e/ ou voluntária, conforme já discutimos anteriormente ao analisar o conteúdo de fala da professora Adhara, e requer uma articulação direta entre as práticas de leitura que ocorrem dentro e fora da escola.

Com relação a esse papel da leitura, enquanto agente mobilizador de ampliação da compreensão/atuação das práticas sociais que se estabelecem fora do contexto escolar, os estudos de Souza, Leite e Albuquerque apontam que:

[...] o processo de didatização da leitura precisa ser feito de modo a garantir que as práticas de leitura, desenvolvidas nesse espaço, se aproximem daquelas realizadas fora dele. Isso implica trazer, para a sala de aula, os contextos significativos de leitura, que envolvem diferentes gêneros presentes no convívio social dos alunos e professores. Cabe à escola, fundamentalmente, levar seus educandos a um processo mais amplo de reflexão acerca das práticas sociais que envolvem a leitura e a escrita, proporcionando aos mesmos o desenvolvimento da capacidade de serem usuários 
efetivos da língua escrita (SOUZA; LEITE; ALBUQUERQUE, 2006, p. 30-311..

Após capturarmos as respostas de cada docente em relação aos objetivos para o ensino da leitura - conforme já descrito no capítulo que versa sobre o percurso metodológico da pesquisa -, oferecemos a cada uma, individualmente, um texto com as respostas da(s) docente(s) anterior(es), de modo a permitir-thes o acesso à resposta dos seus pares quanto à finalidade do ensino da leitura, e solicitamos que tecessem comentários a partir dessas leituras. Ressaltamos que os textos submetidos à leitura e comentários foram aqueles considerados no processo de análise de conteúdo presentes nesse capítulo.

A seguir, apresentaremos os dados coletados e a análise do conteúdo em relação às finalidades do ensino da leitura, a partir do movimento de leitura e comentários das respostas da(s) docente(s) anterior(es), ao que denominamos entrevista com acesso à resposta dos pares (EARP).

\section{Entrevista com acesso a respostas dos pares (EARP)}

14 No primeiro momento, apresentamos à professora Altair o fragmento de resposta dada por Adhara, cujo foco central da fala estava na leitura para favorecer os saberes escolares. Após a leitura do fragmento, Altair fez a seguinte colocação:

Concordo com o que ela disse, e só acrescentando quando ela fala dessa abertura pra leitura, a leitura expande para todas as disciplinas. A gente pode pegar um texto de Ciências, uma pequena parte, e alfabetizar em cima desse trechinho de Ciências. Agora, como a gente tá direcionando para o $1^{\circ}$ ano, tem que pegar algo simples, lúdico, algo gostoso pra que a criança possa ler e ela vai ter essa abertura de mundo. Mas a leitura, ela realmente vai abrir o mundo, vai abrir os espaços em todas as disciplinas. Então, é através da leitura que tudo se abre, uma pseudoleitura, pra falar a verdade. Porque uma criança do $1^{\circ}$ ano, de fato ela não vai ler. Mas se for bem trabalhada, essa pseudoleitura, quando ela chegar na leitura de fato, vai estar pronta (ALTAIR, 2018).

A professora Altair agrega um objetivo mencionado pela professora Adhara, mas mantém uma finalidade de fruição, antes de conhecer a resposta 
da colega para o ensino da leitura. É possível observar isso no trecho: "como a gente tá direcionando para o $1^{\circ}$ ano, tem que pegar algo simples, lúdico, algo gostoso pra que a criança possa ler..." (ALTAIR, 2018).

Um outro aspecto observável no comentário da professora Altair diz respeito a sua menção ao termo "pseudoleitura" que se refere à prática realizada por criança do $1^{\circ}$ ano. Destacamos que o termo parece superado no âmbito acadêmico, a partir de estudos que tratam do comportamento leitor dos(as) estudantes, afinal, não haveria uma falsa leitura (LERNER, 2002). Entretanto, entendemos que a professora faz referência à ação da criança em processo de aquisição da leitura. Mesmo sem a realizar de modo convencional, já desenvolve atitudes leitoras tanto no âmbito escolar quanto nas práticas sociais fora do contexto escolar. Sobre o desenvolvimento do comportamento leitor, Lerner (2002) estabelece que o professor é a referência para a aprendizagem desse comportamento, pois é a partir dele e através dele que as crianças adentram no mundo da leitura.

Ainda nessa proposta de (EARP), passemos aos comentários da professora Nashira em relação às finalidades do ensino da leitura referidas por Adhara e Altair, cujas falas foram direcionadas à aquisição dos saberes escolares, à leitura por prazer e aos conhecimentos prévios. Elementos presentes, em certa medida, nos comentários da professora Nashira conforme segue:

Eu concordo. Realmente os alunos têm um conhecimento prévio. E, a partir do momento que realmente ele lê, isso abrange, é como você não enxergar e de repente ver. Eu tenho uma aluna no $1^{\circ}$ ano que ela entrou e que agora começou a ler palavras. Ela pegou a minha garrafa e fez assim: Tia, aqui tem eco? Ai eu disse: Tem. Aí ela disse assim: Poxa... e aquela palavra não é bola? E fica lendo as palavras. Então, isso é muito significativo pra eles, é uma felicidade. É poder entender os conteúdos, porque a partir do momento que ele lê, vai poder entender Matemática. Porque Matemática, se você lê o enunciado, eles interpretam. Quando o aluno lê, ele consegue resolver outras situações em outras disciplinas (NASHIRA, 2018).

No comentário da Professora Nashira sobre as respostas das colegas que a antecederam, constatamos a presença dos subsídios referidos pela professora Adhara, no que diz respeito à finalidade da leitura, enquanto instrumento mobilizador da compreensão dos saberes escolares e ênfase na existência dos conhecimentos prévios dos estudantes. Ao apresentar uma 
situação de sua sala de aula, nos deparamos com o elemento do prazer referido pela professora Altair, que apresenta o ato de ler como algo significativo, motivo de felicidade para os estudantes.

Já o trecho de fala em que Nashira (2018) afirma: "[...] a partir do momento que realmente ele lê, isso abrange, é como você não enxergar e de repente vê" fez-nos lembrar do livro de literatura de Ruth Rocha (1998) "O menino que aprendeu a ver [...]", que conta a história de um menino, Joãozinho, em suas descobertas sobre a leitura. A narrativa apresenta o momento inicial da leitura como a abertura da verdadeira visão, quando o menino deixa de enxergar as letras e palavras como desenhos sem sentidoe passa a compreender seu significado. A fala da professora também nos remete à ideia de Goulart:

Parece-nos, então, que o processo de apropriação da língua escrita pela criança está relacionado a aprender a transitar pelas duas modalidades da linguagem verbal - oral e escrita -, ajustando-as às situações de uso socialmente relevantes. Esse trânsito deve afirmar e ampliar a experiência discursiva anterior da criança e todos os conhecimentos aí envolvidos, incluindo a experiência de tomar a própria linguagem, ou aspectos dela, como objeto (GOULART, 2006, p. 4511 .

Vejamos, a seguir, os comentários da Professora Zaniah (2018) sobre as respostas das entrevistadas Adhara, Altair e Nashira, quanto às finalidades do ensino da leitura.

É o que eu falei: Ahhh, não com as palavras que estão aqui. Sobre o prazer da leitura, para o aluno ter prazer pela leitura, parte do professor instigar, sabe? [...] Então, vai surgir o interesse e prazer pela leitura (ZANIAH, 2018).

Ao fazer esse comentário, a professora Zaniah identificou sua resposta com a finalidade do prazer, referido pela professora Altair, anteriormente analisada. Entretanto, os elementos apresentados por Zaniah (2018) em um primeiro momento da entrevista de que os(as) alunos(as) "[...] compreendam todas as leituras à sua volta [...]" estão mais próximos dos aspectos presentes na fala de Nashira. Tal identificação com o prazer pode estar relacionada ao fato dela entender que seja prazeroso oportunizar a compreensão das leituras à sua volta. 
Para fechar o bloco de EARP, vejamos como a professora Adhara (2019), comentou as respostas de seus pares em relação à sua finalidade do ensino inicial da leitura.

Além de ter como objetivo despertar o gosto pela leitura, também desejo diagnosticar os conhecimentos prévios, assim como instigá-los a perguntar, querer saber mais [...] (ADHARA, 2019).

No excerto da professora Adhara (2019) "[...] despertar o gosto pela leitura $[\ldots]$ ", temos uma identificação com o que foi anunciado na fala de Altair, que finalidade de ensino da leitura está direcionada ao prazer. Analisamos seu conteúdo de fala anteriormente, pautadas nos estudos de Geraldi (1984) e Cafiero (2005) que destacam a relevância da escola desenvolver estratégias de ensino da leitura que não sejam mecânicas e destituídas de sentido, mas que possibilitem aos(às) estudantes desenvolverem relações prazerosas com o ato de ler.

A professora Adhara (2019) ainda acrescenta: "[...] também desejo diagnosticar e ampliar os conhecimentos prévios, assim como instigá-los a perguntar, querer saber mais". Durante a entrevista individual, Adhara (2018) havia mencionado que costuma instigar os conhecimentos prévios dos(as) estudantes. Ao ter acesso às respostas dos seus pares, retoma a fala do desejo de diagnosticar e ampliar tais saberes e fazê-los querer construir novos. Cafiero (2005), ao tratar do ensino das capacidades leitoras, faz destaque sobre a importância do(a) professor(a) conhecer os elementos constituintes dos conhecimentos prévios dos estudantes:

O leitor opera com um conjunto de conhecimentos que nos acostumamos a chamar de conhecimentos prévios, mas é importante sabermos exatamente que elementos fazem parte desses conhecimentos, para que possamos ajudar o aluno a construílos ou mesmo ajudar a acioná-los no momento da leitura, se ele já os tiver (CAFIERO, 2005, p. 34).

No trecho acima, a autora não apenas se refere à relevância de um diagnóstico quanto aos saberes trazidos pelos(as) estudantes, mas ainda ressalta a importância de ajudar na construção de novos conhecimentos e da sua utilização adequada nos momentos de leitura. Desse modo, apresenta uma perspectiva que não se encerra apenas em pressupostos teóricos, que devem 
nortear o ensino da leitura, mas aponta elementos que precisam ser traduzidos nas práticas alfabetizadoras.

Nesse sentido, acrescentamos a esta discussão alguns achados dos dados de pesquisa que trałam da organização das práticas de ensino inicial da leitura. Três dos sujeitos de nossa pesquisa las professoras Adhara, Altair e Nashira) revelaram algumas dimensões relativas ao modo como organizam suas aulas de leitura para o alcance dos objetivos por elas explicitados ao elencarem os objetivos para o desenvolvimento de leitores(as) competentes. Vejamos:

Então, é claro que partimos da leitura com a criança, considerando que a criança já tem uma leitura de mundo, que chamamos de conhecimento prévio e que instigamos muito isso também (ADHARA, 2018).

$[\ldots]$

Antes de ler, pegar um livro e ver a contracapa, ver quem escreveu, e já no primeiro impacto que pegar um livro, sentir a felicidade que aquele livro pode trazer (ALTAIR, 2018).

[...]

Então eu começo a trabalhar a questão da consciência fonológica e da escrita, e depois parto para leitura em si (NASHIRA, 2018).

Nos trechos de fala das professoras Adhara e Altair, verificamos que as docentes estruturam suas práticas a partir do uso de estratégias antes da leitura - ativam conhecimentos prévios, provocam expectativas e previsões sobre o texto. As estratégias de leitura referidas pelas docentes consistem em objeto de estudo de Solé que defende a importância do desenvolvimento de tais estratégias, assim como de outras, na formação inicial do leitor.

Se as estratégias são procedimentos e os procedimentos são conteúdos de ensino, então, é preciso ensinar as estratégias para a compreensão dos textos. Estas não amadurecem, nem se desenvolvem, nem emergem, nem aparecem. Ensinam-se - ou não se ensinam - e se aprendem - ou não se aprendem (SOLÉ, 1998, p. 70).

Diante do exposto, afirmamos que as professoras Adhara e Altair - mesmo inicialmente se referindo a objetivos para o ensino da leitura direcionados à aprendizagem dos saberes escolares e ao prazer, respectivamente - também direcionam seu fazer pedagógico para a compreensão leitora. Pois, 
ao organizarem suas práticas a partir das estratégias de leitura, fica evidente que oportunizam a interação do(da) estudante/leitor com o texto a partir de uma ação intencional.

Ainda sobre a organização da prática, considerando os objetivos definidos para o ensino da leitura, a professora Nashira (2018), ao citar as atividades que exploram a consciência fonológica e a escrita, evidencia uma prática pedagógica que articula a leitura a outros eixos de ensino da língua portuguesa de maneira mais direta em relação à análise linguística e à produção de textos escritos. Tal ação ancora-se em pressupostos de que o ensino da leitura não deve se dar de forma isolada. A esse respeito, o Ministério da Educação orienta:

[...] promover um ensino com base em planejamento consistente e integrado e que inclua situações favoráveis de aprendizagem focadas. Isto significa contemplar os quatro eixos de ensino e aprendizagem das práticas de linguagem e língua: oralidade, leitura, produção de texto escrito e análise linguística - elementos de discursividade, textualidade, normatividade e apropriação do sistema de escrita alfabética - tendo em vista seu papel em relação à aprendizagem de Língua Portuguesa e dos demais componentes curriculares ao longo da escolaridade dos alunos (BRASIL, 2012, p. 40).

Temos, assim, a relevância de uma prática docente que integre os eixos de ensino da língua portuguesa. Dessa forma, o ensino do eixo leitura - nosso objeto de estudo - deve estar pautado num trabalho conjunto com os demais eixos do ensino de linguagem.

\section{Considerações finais}

Neste artigo buscamos refletir a respeito das finalidades estabelecidas pelas docentes para o ensino da leitura no primeiro ano do ciclo de alfabetização, o que nos permite delinear algumas conclusões sem, no entanto, esgotar as discussões e estudos sobre o objeto em questão.

Afinal, qual a finalidade docente do ensino inicial da leitura? Nosso artigo observou três intenções pedagógicas nas falas das professoras que trataram do ensino do referido eixo no primeiro ano do ciclo alfabetizador: al 
favorecer a aquisição de conteúdos/saberes escolares; b) oportunizar a compreensão de mundo; c) proporcionar a fruição.

As finalidades acima indicadas ancoram-se numa perspectiva interativa entre o texto e o estudante/leitor. Nessa perspectiva, compreendemos que, para as professoras, sujeitos deste artigo, o ensino da leitura não é considerado como um fim em si mesmo, mas consiste na busca por ampliar o alcance de finalidades do ato de ler para o(a) estudante. Portanto, as intenções são que os(as) estudantes estabeleçam relações com os textos para aquisição de saberes escolares e extraescolares, além de proporcionar uma formação leitora que busque/encontre prazer nas práticas de leitura.

No bojo das ações pedagógicas, podemos destacar duas ações relevantes nas falas das docentes que podem realçar o seu compromisso com a formação do(a) leitor(a): 1) a mobilização de um conjunto de estratégias de leitura que enfatizem a valorização dos conhecimentos prévios dos(das) estudantes, e 2) o reconhecimento de que o ensino da leitura se efetiva de modo integrado aos demais eixos de ensino da língua portuguesa. Esse cenário, ajuda-nos a compreender que práticas docentes se coadunam com as finalidades do ensino inicial da leitura, por elas referidas.

Finalizamos este texto, porém, não encerramos o debate. Almejamos que a temática seja refletida em diferentes contextos de produção de saber, com vistas ao fortalecimento dos sentidos para o fazer docente, o que pode engendrar estratégias de ensino consistentes com repercussão favorável nas aprendizagens, não só da leitura, mas nos diferentes eixos didáticos.

\section{Nota}

1 Os dados referentes à Avaliação Diagnóstica/2017 e da ANA/2016 foram disponibilizados pelo Núcleo de Avaliação do Recife em julho de 2018.

\section{Referências}

ADHARA. Entrevista. Recife (Pernambuco), 2 out. 2018; 5 mar. 2019.

ALTAIR. Entrevista. Recife (Pernambuco), 9 out. 2018. 
BARDIN, Laurence. Análise de conteúdo. Lisboa: Edições 70, 1977.

BRANDÃO, Ana Carolina Perrusi. $\bigcirc$ ensino da compreensão e a formação do leitor: explorando as estratégias de leitura. In: BARBOSA, Maria Lúcia Ferreira de Figueiredo e SOUZA, Ivane Pedrosa de (org.). Práticas de leitura no ensino fundamental. Belo Horizonte: Autêntica, 2006.

BRASIL. Ministério da Educação. Secretaria de Educação Básica. Elementos conceituais e metodológicos para definição dos direitos de aprendizagem e desenvolvimento do ciclo de alfabetização $\left(1^{\circ}, 2^{\circ}\right.$ e $3^{\circ}$ anos) do Ensino Fundamental. Brasília: MEC, SEB, 2012. Disponível em: http://portal.mec.gov.br/component/docman/?task=doc_ download\&gid=12827\&ltemid. Acesso em: 22 mar. 2018.

CAFIERO, Delaine. Leitura como processo: caderno do professor. Belo Horizonte: Ceale/ FaE/UFMG, 2005.

CAFIERO, Delaine. Letramento e leitura: formando leitores críticos. In: RANGEL, Egon de Oliveira e ROJO, Roxane Helena Rodrigues (coord.). Língua portuguesa: ensino fundamental: Brasília: Ministério da Educação, Secretaria de Educação Básica, 2010.

GERALDI, João Wanderley. $\mathbf{O}$ texto em sala de aula: leitura e produção. 3. ed. Campinas: Assoeste, 1984.

GOULART, Cecília. Letramento e modos de ser letrado: discutindo a base teórico-metodológica de um estudo. Revista Brasileira de Educação, Rio de Janeiro, v. 11 n. 33 set./dez. 2006.

KRAMER, Sônia. Alfabetização, leitura e escrita: formação de professores em curso. São Paulo: Ática, 2001.

$\mathrm{KOCH}$, Ingedore Grünfeld Villaça. Desvendando os segredos do texto. São Paulo: Cortez, 2002.

LAJOLO, Marisa. Do mundo da leitura para a leitura do mundo. 6. ed. São Paulo: Editora Ática, 2004.

LEAL, Telma Ferraz; MELO, Kátia Reis. Planejamento do ensino da leitura: a finalidade em primeiro lugar. In: BARBOSA, Maria Lúcia Ferreira de Figueiredo;

LERNER, Délia. Ler e escrever na escola: o real, o possível e o necessário. Tradução Ernani Rosa. Porto Alegre: Artmed, 2002.

NASHIRA. Entrevista. Recife (Pernambuco), 26 out. 2018. 
OlIVEIRA, Maria Marly de. Metodologia Interativa: um processo hermenêutico dialético. Interfaces Brasil/Canadá. Revista Brasileira de Estudos Canadenses, Porto Alegre, v. 1, n. 1, 2001.

ROCHA, Ruth. O menino que aprendeu a ver. 2. ed. São Paulo: Quinteto Editorial, 1998. SOARES, Magda. Letramento: um tema em três gêneros. Belo Horizonte: Autêntica, 1998. SOARES, Magda. Projeto Alfaletrar- Ler e escrever, um direito de toda criança, 4 ed. Secretaria de Educação Lagoa Santa, 2015 (Apostila).

SOARES, Magda. Alfabetização: a questão dos métodos. São Paulo: Contexto, 2016.

SOLÉ, Isabel. Estratégias de leitura. Porto Alegre: Artes Médicas, 1998.

SOUSA, Alexsandra Felix de Lima. Leitura no primeiro ano do ciclo de alfabetização demandas de formação continuada de docentes da rede municipal de ensino do Recife. 2019. 112 fl. Dissertação (Mestrado em Educação) - Programa de Pós-Graduação em Educação, Universidade de Pernambuco, Nazaré da Mata, 2019.

SOUZA, Ivane Pedrosa de LEITE, Tânia Maria Rios; ALBUQUERQUE, Eliana Borges Correia de. Leitura, letramento e alfabetização na escola. In: BARBOSA, Maria Lúcia Ferreira de

22 Figueiredo e SOUZA, Ivane Pedrosa de (org.). Práticas de leitura no ensino fundamental. Belo Horizonte: Autêntica, 2006.

TRAVAGLIA, Luiz Carlos. Concepções de linguagem. In: TRAVAGLIA, Luiz Carlos. Gramática e interação: uma proposta para o ensino de gramática no $1^{\circ}$ e $2^{\circ}$ graus. São Paulo: Cortez, 1996.

ZANIAH. Entrevista. Recife (Pernambuco), 21 nov. 2018.

Ms. Alexsandra Felix de Lima Sousa Universidade de Pernambuco | Campus Mata Norte (Brasil) Programa de Pós-Graduação em Educação Grupo de Estudos Em Educação, Letramento, Oralidade e Alfabetização (ELOA) Orcid id: https://orcid.org/0000-0001-5715-8114 E-mail: ale.sandrafsousa@educ.rec.br 
Profa. Dra. Débora Amorim Gomes Costa-Maciel Universidade de Pernambuco | Campus Mata Norte (Brasil) Programa de Pós-Graduação em Educação Grupo de Estudos Em Educação, Letramento, Oralidade e Alfabetização (ELOA) Orcid id: https://orcid.org/0000-0002-6408-1626 E-mail: deboracostamaciel@gmail.com

Recebido 18 mar. 2021 Aceito 28 abr. 2021 